\title{
Incentives for HIV testing at the workplace in the auto- motive industry in the Nelson Mandela Bay Municipality: Ethical considerations
}

\author{
M Weihs, ${ }^{1,2} \mathrm{PhD} ;$ A Meyer-Weitz, ${ }^{2} \mathrm{PhD} ;$ F Baasner-Weihs, ${ }^{3}$ MPhil \\ ${ }^{1}$ Social Aspects of HIV/AIDS Research Alliance (SAHARA) and HIV/AIDS, Sexually Transmitted Infections and TB (HAST), Human Sciences Research \\ Council (HSRC), Port Elizabeth, South Africa \\ ${ }^{2}$ Discipline of Psychology, School of Applied Human Sciences, University of KwaZulu-Natal, Durban, South Africa \\ ${ }^{3}$ HIV and AIDS Research Unit, Department of Research and Engagement, Nelson Mandela Metropolitan University, Port Elizabeth, South Africa
}

Corresponding author: Martin Weihs (martin.weihs1@gmail.com)

\begin{abstract}
Comprehensive HIV and AIDS workplace programmes made use of substantial lottery incentives in HIV counselling and testing drives to promote HIV testing at four companies in the automotive industry in the Nelson Mandela Bay Municipality. The main aim was to use lottery incentives to increase uptake for HIV testing. This would help to define company HIV prevalence and ensure timely support, care and treatment of employees. In total, 1324 employees, making up about $90 \%$ of the total staff, were tested for HIV in the four companies during wellness testing days. In order to gain an understanding of employees' experiences of the lotteries as part of the HIV counselling and testing drive, quantitative data were collected among a total of 414 employees, and 17 interviews were conducted in the four companies. In this article, we investigate the issue of whether the lotteries unduly influenced the employees' participation in workplace HIV testing, and an approach to resolving an identified ethical dilemma is presented. The ethical question as to whether lottery incentives contribute to undue coercion was explored using both a utilitarian and a deontological approach. The analysis concluded that the use of lotteries to encourage HIV testing in the workplaces of the automotive industry in the Nelson Mandela Bay Municipality can be deemed morally acceptable.
\end{abstract}

S Afr J Bioethics Law 2017;10(1):11-14. DOI:10.7196/SAJBL.2017.v10i1.531

Globally, $90 \%$ of people living with HIV are in the most productive period of their lives, be they workers, managers or employers. ${ }^{[1,2]}$ Health management of employees is therefore a common imperative for companies that do business in regions where HIV impacts employees and communities. ${ }^{[3]}$ No accurate estimates exist about the extent of the current HIV prevalence within the South African (SA) workforce, but the Health and Sciences Research Council (HSRC) has estimated that 6.4 million people were living with HIV in 2012 in SA, and that only $44.8 \%$ were aware of their HIV status. ${ }^{[4]}$ Therefore, it can be assumed that many of those currently infected are not yet seeking treatment. Private-sector HIV/AIDS workplace programmes (WPPs) in SA have evolved considerably, ${ }^{[5]}$ and by encouraging HIV counselling and testing (HCT) in the workplace, companies can define their HIV prevalence rate more accurately. This is a prerequisite for efficient and effective HIV and AIDS management ${ }^{[6]}$ aimed at helping to diminish morbidity and mortality. ${ }^{[7]}$ Furthermore, this also allows for the support of the National Health Promotion Policy and Strategy of $2015-2019,{ }^{[8]}$ and the National Strategic Plan on HIV, STIs (sexually transmitted infections) and TB (tuberculosis) 2012 - 2016, that together aimed for $80 \%$ of adults in SA to know their HIV status by the year $2016 .^{[9]}$

\section{Lotteries to encourage HIV testing in the workplace as part of HIV/AIDS workplace programmes}

During a project run by the Deutsche Gesellschaft für Internationale Zusammenarbeit (GIZ) GmbH and the Automotive Industry Develop- ment Centre Eastern Cape (AIDC EC) from 2008 to 2016, several suppliers of the automotive industry based in the Nelson Mandela Bay Municipality have benefitted from support with the implementation of comprehensive HIV and AIDS WPPs. One of the main AIDC EC-GIZ project key performance indicators of these HIV and AIDS WPPs was the workplace HCT uptake rate in the companies at the end of the 1-year WPP implementation process. Inspired by companies that seemed to have successfully made use of lottery incentives ${ }^{[10]}$ in order to increase workplace HCT uptake, the project team looked at using lotteries to motivate employees to test for HIV in the workplace. However, there was a lack of evidence on how these lotteries influenced employees' decisions to test for HIV, and the suggestion of offering such incentives sparked off controversial discussions within the project team. Therefore, a study was conducted to accompany this project in order to obtain evidence on how lottery incentives influence employees' HIV workplace testing behaviour.

In all four companies that participated in the study, comprehensive HIV/AIDS WPPs of the same standard had been implemented independently. Employees had participated in at least 5 months of workplace HIV/AIDS interventions that included, for example, the development of HIV/AIDS policies and activities in order to educate workers about HIV prevention, treatment and care. A post-test only quasi-experimental, explanatory, mixed-methods approach was adopted in which quantitative data for the experimental studies were first collected at the four companies, followed by qualitative studies conducted in the same companies in order to gain a deeper 
understanding of employees' lottery experiences as part of the HCT drive. Quantitative data were collected among a total of 414 shopfloor workers in the four companies on the same day that the HCT drive dates and the lotteries' incentives were announced to staff. In-depth interviews were conducted about 2 weeks after the HCT drive events at the same companies. Seventeen shop-floor workers who had been exposed to the lottery incentives were interviewed, irrespective of whether they had sought HIV testing or not. Leaflets, posters and peer-education sessions were used to make all workers aware of the fact that HCT and three other health tests (body mass index, blood pressure and blood sugar level) would be offered at no cost during the $\mathrm{HCT}$ drives, during worktime. For more information about the methodology of the quantitative and qualitative studies, see the respective publications. ${ }^{[11-13]}$ In total, 1324 employees were tested for HIV in the four companies during the HCT drives, making up about $90 \%$ of the total staff. This can be seen as a higher-thanaverage HIV workplace testing rate. ${ }^{[1,3,14,15]}$

\section{Ethical concerns around lotteries for HIV testing in the workplace}

Fulfilling the entry requirements for the lottery made employees eligible to win gift cards of considerable value (first prize R2 000, second prize R500, and 10 extra R100 prizes). In addition, they each received a t-shirt. The first prize amounted to nearly half a month's normal wage for a participant (shop-floor workers in the four companies earned on average ZAR5 000 per month).

A first concern is that lottery incentives may undermine the moral values that form an important foundation of our open society, as discussed in an article by Cameron and Van der Merwe. ${ }^{[16]}$ However, the results of our study showed that the announcement of lotteries made shop-floor workers develop a stronger intention to participate in workplace HIV testing, through anticipation of stronger social support and encouragement from partners, friends and colleagues. Therefore, participation in HCT did not seem to hinge only on the likelihood of winning a prize. ${ }^{[13]}$

A further concern was that offering lotteries with substantial prizes to encourage participation in workplace HIV testing raises the question of whether such incentives put undue pressure on employees to volunteer for testing. Lotteries have been found to improve participation in desirable, healthy behaviours, particularly among staff with lower levels of income: ${ }^{[17]}$ it seems, therefore, that lottery approaches may be a particularly useful way to encourage higher rates of engagement in health- and wellness-focused behaviour among lower-income employees. However, employees' freedom of choice can be curtailed or manipulated by lottery incentives, and participants can be coerced in this way to participate in HIV testing at the workplace. Lotteries have been described as 'coercive', as they can be seen as putting undue pressure on people to participate in HIV testing. ${ }^{[16]}$ This may be especially so in the case of a person in desperate need of extra financial income.

\section{Resolving the ethical dilemma around lotteries for HIV testing in the workplace}

The ethical dilemma stemming from the use of lottery incentives to encourage workplace HIV testing participation can be described from the perspectives of both the employers and their employees. Organisations may see the lotteries as an effective means of persuading employees to participate in workplace HCT. Some studies and grey literature suggest that when lottery incentives were offered to employees, the workplace HIV-testing intention significantly improved ${ }^{[11]}$ or HIV-testing behaviour increased. ${ }^{[3,10]}$ This suggests that some employees would probably not participate in workplace $\mathrm{HCT}$ if lottery incentives were not offered. Therefore, making use of lotteries allows the company to capture more reliable and muchneeded data about their company's HIV prevalence rates, as more employees are ready to test. But from the employee point of view, some might test HIV-positive and have to bear major emotional distress, and possibly encounter stigma and discrimination. Therefore, the lotteries might indirectly have pushed them into a situation for which they are not ready. Not making use of lotteries might protect these employees from this level of distress, but companies then might not be able to ensure that all employees know their status, nor would they be able to determine a reliable measure of their workforce's HIV prevalence.

This problem shows the characteristics of an ethical dilemma, ${ }^{[18]}$ as there are two similarly convincing obligations. Firstly, managers have an obligation to make sure that their company stays globally competitive, and this, therefore, requires the collection of adequate and reliable data for the reduction of the HIV and AIDS impact on employees and the company. Secondly, companies are obliged to offer necessary conditions for all their employees to be in a position to make autonomous decisions relating to HIV testing and test outcomes. In short, management has the moral duty to protect employees and the company from the impact of HIV and AIDS, but it is also morally obliged to respect employees' autonomy in decisionmaking regarding HIV testing. The answer to whether or not to use lottery incentives for workplace HCT is therefore not at all clear cut.

There are numerous approaches to resolving apparent ethical dilemmas. We examine the options from two perspectives: firstly, the utilitarian approach, a form of consequentialism whereby the consequences of a behaviour are analysed in order to ascertain whether it can be judged as being wrong or right; and secondly, the deontological approach, which looks at the moral content of the behaviour itself rather than at its outcomes.

Results from the quantitative data suggest that the announcement of lotteries made shop-floor workers develop a stronger intention to participate in workplace HIV testing, through anticipation of stronger social support and encouragement from partners, friends, colleagues and the company, rather than by attracting them to HIV testing solely to win a prize. ${ }^{[13]}$ Fig. 1 shows in a simplified way how the theory of planned behaviour (TPB) used in our study as a framework for predicting intended use of HCT in the workplace helped to highlight how far the lottery incentives influenced workers' behaviour intention to participate in workplace HCT. ${ }^{[1]}$

These findings are in line with several studies that have shown that the relationship between incentives and targeted behaviour can go beyond the limits of such incentives' economic effects. ${ }^{[20-23]}$ The qualitative data collected in the four companies revealed that the introduction of the lotteries renewed employees' personal interest in HCT. The excitement created by the lottery incentives facilitated social interactions and seemed to mitigate the burden of HIV stigma, both in the workplace and at home. The following quotes show how the lottery incentives facilitated open communication about HCT in the workplace and at home: 


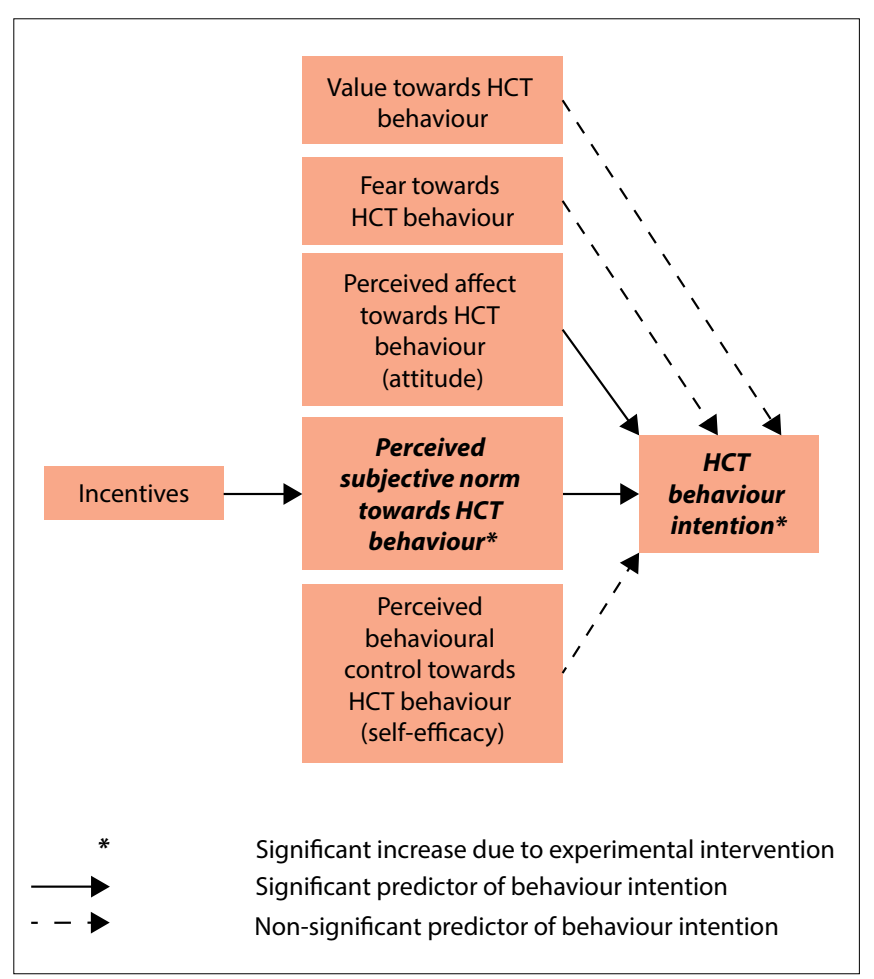

Fig. 1. TPB for workplace HCT with incentives, experimental group, setting $1 .{ }^{[11,19]}$

'Because as I said, most, most of us, most of us, were really afraid, you know, the stigma that is involved - because you hear what people have to say about it, you know, there're many myths about this thing and stuff like that - but because of these prizes, you know, euhmmm ... like for me, I speak personally, I don't know for the other people, but really it did a big thing, ... in going for the testing.'

'Yes exactly, you will and like people who's going, you can even talk about it [workplace $\mathrm{HCT}$ ], you can even ask, you can even like make some jokes, you know, about it, so it's like, it's more confident, like you are confident about this. It becomes easier, every day, every day, it is easier.'

'She [the partner] did very much encourage me, she said go for it, do it.'

The following quotes illustrate how the HCT campaign, in the context of the lottery incentives, was transformed into a group 'project' where mutual encouragement and strong peer pressure to test played a role in the uptake of HCT:

'Because if one person sees, boy there's lots of people going, they gonna go.'

'No, there was no one who exactly was pushing me. But, at first when I heard about this programme, no I was just OK I will see, but I wouldn't go for testing, but as I see the majority of people go, coming in there, testing, coming out, excited, wonderful, they discuss it and all that stuff. I was like, hey, it's like I was the only one who didn't go for testing but, I wasn't planning to go to do testing this year. I was planning to do maybe ... like next year ... but I, I felt pressurised ... They didn't say ... but I did go for testing.'

Therefore, following a utilitarian line of argument, the use of lotteries to encourage workplace HIV testing can be deemed morally justifiable, as it seems that the vast majority of the employees were in favour of the lotteries, and that far more benefits than harm may stem from workplace HCT when lottery incentives are offered. ${ }^{[12]}$ The above findings are in line with Cameron and Van der Merwe's ${ }^{[16]}$ findings that indicated that there was no detrimental issue with using lotteries to encourage HIV testing among students. The vast majority of the students surveyed were in favour of the lotteries. The thought of winning a prize was an encouragement, but students also felt they were able to act in their own best interest and did not feel they were being coerced in any way. ${ }^{[16]}$

From a deontological perspective, autonomy is a first-order human right, enshrined in SA's Constitution. If a person's autonomy is to be respected, companies have to allow individuals to make decisions and to act upon them. ${ }^{[24]}$ It can be argued that the offering of financial incentives to a person in desperate need could be seen as inherently exploitative and not consistent with the principle of autonomy. Although HCT counsellors have to be specially trained to ensure that they are able to counsel people properly and enable employees to make autonomous decisions, the legitimacy of the written consent needed for HCT can be of concern when lottery incentives are involved. However, the use of lotteries can be found to be ethically correct when companies make sure that employees are in a position to make an autonomous choice, and that substantial risk of serious harm is prohibited. ${ }^{[25]}$ To control the risk of serious harm, a deontologist would want to limit the use of lotteries to environments where individuals have been offered sufficient awareness opportunities and have been properly informed about the consequences of being tested HIV positive, and about their rights, as well as how to access treatment and care. This should be the case in companies where comprehensive HIV and AIDS workplace programmes are implemented as per the requirements of SA legislation. ${ }^{[26,27]}$

\section{Conclusion}

The results show that the use of lotteries to encourage HIV testing in the workplaces of the automotive industry in the Nelson Mandela Bay Municipality can be deemed morally acceptable. There seems to be a small risk of the incentive influencing employees in financial need to participate in HIV testing, when they would not do so otherwise. The principle underpinning people's rights may not be trampled on merely because one anticipates good results. This tenet cannot be put aside when one considers the situation of HIV-and AIDS-infected and-affected employees in SA. However, if incentives are used in companies that have implemented comprehensive HIV and AIDS WPPs, and if companies have ensured that counsellors are informed about the use of incentives, then employees should be in a position to make autonomous and beneficent choices. This - and the fact that participation in HCT did not seem to hinge only on the likelihood of winning a prize - sheds a positive light on lottery incentives as used in comprehensive HIV and AIDS WPPs' HCT drives. Lotteries could help companies to fight HIV and AIDS more efficiently, and so be of benefit to all.

Acknowledgements. We are grateful to the companies and employees who participated in the study. We would also like to thank the AIDC $\mathrm{EC}$, the GIZ GmbH and the HSRC for supporting the research.

1. South African Business Coalition on HIV/AIDS. HIV and Business Overview. South African Business Coalition on Health and AIDS. 2015. http://www.sabcoha.org/ hiv-business-overview/ (accessed 5 May 2015). 
2. Setswe GKG. Best practice workplace HIV/AIDS programmes in South Africa: A review of case studies and lessons learned. Afr J Prim Health Care Fam Med 2009;1(1):1-6. http://dx.doi.org/10.4102/phcfm.v1i1.30

3. George G, Quinlan T. 'Health management' in the private sector in the context of HIV/AIDS: Progress and challenges faced by company programmes in South Africa. Sustain Dev 2009;17(1):19-29. http://dx.doi.org/10.1002/sd.366

4. Shisana O. HIV/AIDS in South Africa: At last the glass is half full. Plenary Session 3, 20 June 2013, 6th SA AIDS Conference, Durban. 2013. http://www.hsrc.ac.za/ en/media-briefs/hiv-aids-stis-and-tb/plenary-session-3-20-june-2013-hiv-aidsin-south-africa-at-last-the-glass-is-half-full (accessed 5 May 2015).

5. Global Business Coalition, International Finance Corporation. Fighting HIV/AIDS in the Workplace: A Company Management Guide. Global Business Coalition on HIV/ AIDS, Tuberculosis and Malaria (GBC) and the International Finance Corporation (IFC), 2010. http://www.businessfightsaids.org/report/2355/ (accessed 13 June 2015).

6. United Nations Programme on HIV and AIDS. The Private Sector Responds to the Epidemic: Debswana - A Global Benchmark. Geneva: Joint UNAIDS, 2002. http:// data.unaids.org/publications/irc-pub02/jc769-debswana_en.pdf (accessed 5 May 2015).

7. Lee R, Cui RR, Muessig KE, Thirumurthy H, Tucker JD. Incentivizing HIV/STI testing: A systematic review of the literature. AIDS Behav 2014;18(5):905-912. http:// dx.doi.org/10.1007/s10461-013-0588-8

8. Department of Health. The National Health Promotion Policy and Strategy 2015 - 2019. Pretoria: National Department of Health, 2014

9. South African National AIDS Council. The National Strategic Plan (NSP) 2012 - 2016. Johannesburg: South African National AIDS Council, 2012. http:// sanac.org.za/resources/cat_view/2-nsp (accessed 29 October 2016).

10. Kaiser Health News. Wall Street Journal Examines Brewing Company SABMiller's Campaign to Increase HIV Testing Among its South African Employees. KHN morning briefing. 2006. http://khn.org/morning-breakout/dr00039281/ (accessed 9 August 2015).

11. Weihs $M$. The influence of lottery incentives on workplace HIV testing in the automotive industry in the Nelson Mandela Bay Municipality. PhD thesis. Durban: University of KwaZulu-Natal, 2016.

12. Weihs $M$, Meyer-Weitz A. A lottery incentive system to facilitate dialogue and social support for workplace HIV counselling and testing: A qualitative inquiry. SAHARA J 2014;11(1):116-125. http://dx.doi.org/10.1080/17290376.2014.937739

13. Weihs M, Meyer-Weitz A. Do employees participate in workplace HIV testing just to win a lottery prize? A quantitative study. South Afr J Hum Resour Manag 2016;14(1):1-8. http://dx.doi.org/10.4102/sajhrm.v14i1.722

14. Connelly P, Rosen S. Provision of antiretroviral therapy by the private sector. Lancet 2005;365(9475):1925-1926. http://dx.doi.org/10.1016/S0140-6736(05)66654-8
15. George G. Workplace ART programmes: Why do companies invest in them and are they working? Afr J AIDS Res 2006;5(2):179-188. http://dx.doi. org/10.2989/16085900609490378

16. Cameron DA, Van der Merwe H. Are students being coerced into testing for HIV? Ethical considerations related to offering incentives for HIV counselling and testing at tertiary institutions in South Africa. S Afr J Bioeth Law 2012;5(2):95-97. http://dx.doi.org/10.7196/SAJBL.197

17. Haisley E, Volpp KG, Pellathy T, Loewenstein G. The impact of alternative incentive schemes on completion of health risk assessments. Am J Health Promot 2012;26(3):184-188. http://dx.doi.org/10.4278/ajhp.100729-ARB-257

18. Van Niekerk AA, Kopelman LM, eds. Ethics \& AIDS in Africa: The Challenge to our Thinking. Cape Town: New Africa Books, 2005.

19. Ajzen I. The theory of planned behaviour. Organ Behav Hum Decis Process 1991;50(2):179-211. http://dx.doi.org/10.1080/17437199.2014.883474

20. Kane RL, Johnson PE, Town RJ, Butler M. A structured review of the effect of economic incentives on consumers' preventive behaviour. Am J Prev Med 2004;27(4):327-352. http://dx.doi.org/10.1016/j.amepre.2004.07.002

21. Marcus AC, Crane LA, Kaplan CP, et al. Improving adherence to screening followup among women with abnormal Pap smears: Results from a large clinic-based trial of three intervention strategies. Med Care 1992;30(3):216-230. http://dx.doi. org/doi: 10.1097/00005650-199203000-00004

22. Melnikow J, Paliescheskey M, Stewart GK. Effect of a transportion incentive on compliance with the first prenatal appointment: A randomized trial. Obstet Gynecol 1997;89(6):1023-1027. http://dx.doi.org/10.1016/10.1016/S0029-7844(97)00147-6

23. World Bank. A cash transfer program reduces HIV infections among adolescent girls. The World Bank Development Research Group. http://siteresources.worldbank org/DEC/Resources/HIVExeSummary(Malawi).pdf (accessed 19 September 2015).

24. Botes A, Otto M.Ethical dilemmas related to the HIV-positive person in the workplace. Nurs Ethics 2003;10(3):281-294. http://dx.doi.org/10.1191/0969733003ne606oa

25. Emanuel EJ. Ending concerns about undue inducement. J Law Med Ethics 2004;32(1):100-105. http://dx.doi.org/10.1111/j.1748-720X.2004.tb00453.x

26. Department of Labour. South African Code of Good Practice on HIV and AIDS and the World of Work in Employment Equity Act, No. 55 of 1998. Republic of South Africa: Department of Labour, 2012. http://www.labour.gov.za/DOL/downloads/legislation/ acts/employment-equity/hivaidstechnicalguide.pdf (accessed 5 May 2015).

27. Department of Labour. Technical Assistance Guidelines on HIV and AIDS and the World of Work. Pretoria: Department of Labour Republic of South Africa Chief Directorate of Communication, 2012. http://www.labour.gov.za/DOL/documents/ useful-documents/employment-equity/technical-assistance-guidelines-on-hivand-aids-and-the-world-of-work-2012 (accessed 23 June 2015). 